\title{
El futuro no tan incierto de la Sanidad Militar en misiones de paz
}

\section{Sr. Director:}

El objetivo de la Medicina actual es alargar la vida humana y mejorar su calidad, es modesto, si se tiene en cuenta que para Francis Bacon (1561-1626), lord Férula, el objetivo de la Ciencia era conseguir la inmortalidad. Con esta Carta al Director no queremos conseguir lo mismo para la Sanidad Militar que el padre del empirismo para la vida pero sí aportar posibles soluciones a las actuales dificultades de cobertura sanitaria en operaciones. Salvo en EEUU cuyo gasto en Defensa es el $44 \%$ del mundial, en los demás países en Zona existe carencia en el despliegue de personal médico; así en el hospital de campaña británico principal en Helmand, Afganistán, el 70\% del personal han sido reservistas en 2011; en el contingente canadiense hay un déficit de $35 \%$ en los médicos que despliegan y el problema está creciendo a medida que continúa su misión en Afganistán.

Fue en otoño 2008 que la publicación médica española más leída (Correo Médico) publicó el titular : "El Ejercito cuelga el cartel de 'no hay médicos'" Desde entonces, han sido varias Cartas al Director en esta nuestra Revista escritas por compañeros de sanidad las que han abordado el tema de la falta de personal médico para desplegar en Misiones de Paz, también en otras publicaciones (Revista Ejército, Atenea, entre ellas) varios militares de las Armas que han tenido relación con la Sanidad Militar han procurado posibles soluciones al problema; existe un debate abierto sobre el futuro de la Sanidad Militar. Todos los artículos coinciden en que no existen en la práctica suficientes nuevos ingresos (no parece cubierto el relevo generacional) y la disponibilidad de los existentes se reduce mes a mes, ya sea porque la edad propicia de despliegue es superada o por las crecientes excedencias que este personal solicita.

Pero también es cierto que algunas de las soluciones propuestas en estas publicaciones han tenido eco, como la de contar con nuestros Reservistas para misiones, la consecución de la especialidad de Medicina ingresando sin titulación universitaria previa y la externalización de ciertas actividades de la cadena de apoyo asistencial (aprovechamiento de recursos) está en marcha desde hace tiempo. Los Reservistas han recibido con fecha 18 de marzo pasado una carta del Subdelegado de Defensa consultando su disposición y voluntariedad para participar en misiones en el extranjero con el ruego de comunicar su conformidad no más tarde del 28 de marzo. En un BOD de este mes de Abril hemos visto publicada la modificación de la Disposición Adicional sexta de la Ley 39/2007, de 19 de noviembre, de la carrera militar, con la adición de un nuevo apartado que permite tener cubierto nuestro relevo generacional, captando personal desde el pregrado; no cabe duda de que habrá nuevos ingresos y se cubrirán todas las plazas.

El pasado mes de marzo se envió desde Zona (LH XVI) a un militar para una intervención quirúrgica en el Role4 en T.N. y no pudo ser realizada con la premura requerida porque cua- tro especialistas en Anestesia y Reanimación se hallaban involucrados en la misión afgana, ora porque estaban en Zona, ora porque estaban disponiendo su despliegue. La IGESAN ya no refuerza a los Ejércitos sino que, prácticamente, aporta casi todo el personal médico para el despliegue. Es hora de plantearse la disminución de efectivos médicos en las Misiones de Paz en tanto no aparezcan las nuevas incorporaciones y añadir otros profesionales capaces de dar una segunda oportunidad a la baja en combate. Es sabido que algunos enfermeros han sido destacados en solitario a las FOB (Bases Avanzadas) de Ludina y Moqour en la ruta Lithium pero esta no es una solución definitiva. La solicitud de personal sanitario en los convoyes y patrullas es la que crea más discusión y es que existe un argumento irrebatible para una óptima primera asistencia a la baja en combate: la supervivencia pasados los primeros cuatro minutos tras una parada cardíaca se considera casi nula (un 2\%), llegando al $80 \%$ si se hace en el primer minuto. Esta necesaria movilidad del que asiste no se consigue con una Célula de Estabilización a cola de convoy cuando, mientras tanto, se recibe fuego enemigo; deberíamos, como hacen otros países con más medios, de situar paramédicos -titulación equivalente a los Técnicos en Emergencias Sanitarias (TES) de nuestra patria- cada tres o cuatro vehículos: alguien que sea capaz de detener una hemorragia profusa con garantías de supervivencia, de situar en primera línea de conflicto técnicas de resucitación cardiopulmonar y de estabilización de pacientes críticos, en definitiva, de prestar atención prehospitalaria de emergencia.

Existe un rechazo generalizado a la incorporación de los TES a las misiones ya que la Doctrina Sanitaria Conjunta no contempla esta posibilidad y además faltaría definir el campo competencial y de actuación del Técnico en Emergencias (ética, deontológica y legislativamente) en Operaciones de Apoyo a la Paz. Para la primera evidencia, aunque mi experiencia en staff sanitario es poca, se podría realizar una adenda et corrigenda a la Doctrina en su próxima revisión que contemplara la participación de los TES. Para la segunda evidencia trataré, con el concurso de varios jurídicos militares que han dado el visto bueno a los argumentos empleados, de exponer claramente que existe legalmente el respaldo para una posible introducción de los TES en Zona de Operaciones. No obstante uno de cada tres días las tropas españolas en Afganistán sufren algún tipo de encuentro con los insurgentes.

La capacitación profesional del Técnico viene regulada por los programas de formación específica y en sus competencias se incluye la prestación de SVB en solitario y de SVA como colaborador de médico y enfermero, pero también puede realizar en situaciones de urgencia vital y amparado por el Estado de Necesidad justificante, determinadas actuaciones, aunque excedieran levemente su techo competencial; podrán ser realizadas siempre que se cumplan estos requisitos: 


\section{Cartas al Director}

1. La técnica a realizar debe haber estado establecida como la adecuada en aquella situación.

2. El técnico debe conocerla correctamente, debe haberla ensayado con éxito y haber recibido una formación específica que garantice que la va a realizar con éxito y con las máximas garantías para el paciente.

3. No puede caber otra posibilidad, en esta circunstancia, que realizar esta técnica. Las consecuencias de no realizar esta técnica pueden llevar al paciente a la muerte o dejarle graves secuelas.

4. No debe haber médico ni enfermero en el lugar ni posibilidad de que puedan acudir en un tiempo razonable.

5. Inmediatamente debe trasladarse al paciente al Centro Hospitalario más próximo y con las atenciones que requiera.

Hablamos, en cualquier caso, de situaciones de urgencia en las que no es posible contar con la presencia de otro personal titulado, la acción salvadora posea animus salvationis y siempre que la técnica a realizar se domine de un modo seguro y esté indicada. En este caso nos basamos en la eximente del Art. 20.5 del Código Penal: "Están exentos de responsabilidad criminal: ... El que, en estado de necesidad, para evitar un mal propio o ajeno lesione un bien jurídico de otra persona o infrinja un deber, siempre que concurran los siguientes requisitos:

Primero. Que el mal causado no sea mayor que el que se trate de evitar.

Segundo. Que la situación de necesidad no haya sido provocada intencionadamente por el sujeto.

Tercero. Que el necesitado no tenga, por su oficio o cargo, obligación de sacrificarse".

En otras palabras, para que se pudiera sancionar un posible delito al atender a una baja en combate tiene que darse una conducta típica, antijurídica y reprochable, si falta alguno de estos requisitos deja de ser delito y por tanto no puede ser castigado. La conducta del TES al atender al herido no sería reprochable y en ese momento también deja de ser antijurídica - que no es contra derecho - porque actuó en un estado de necesidad que se justifica; el TES actúa para salvaguardar un bien jurídico ajeno, la vida o la integridad de un compañero. Solo incurriría en delito por denegación del deber de socorro al omitir una obligación que le es dada.

El Técnico en TN. realiza trabajos de atención sanitaria inmediata a las víctimas de un siniestro pero, además, entre sus capacidades se incluye una (Art. 5 apartado o) del REAL DECRETO 1397/2007, de 29 de octubre) que puede hacer la asistencia en Z.O. uno de sus campos de actuación competenciales: "Adaptarse a diferentes puestos de trabajo y nuevas situaciones laborales originados por cambios tecnológicos y organizativos en la prestación de los servicios".

La carencia de efectivos médicos desplegables debería dar la posibilidad a dejar a estos Oficiales en Puestos de Socorro Fijos, incluidas las Bases Operativas Avanzadas afganas de Muqur y Ludina y permitir que los TES realicen el apoyo a los convoyes, no como lenitivo sino con todas las garantías sanitarias para nuestras tropas - no hay que olvidar que las salidas de la Base llevan inherentes que sea posible un MEDEVAC -. Bastaría desplegar, entonces, 1 ó 2 médicos en Líbano y 2 ó 3 médicos en Afganistán ya que en el primer caso existe un Role 2 en Base Cervantes y en el segundo las bajas son recibidas en Herat en menos de una hora. Hay que tener en cuenta que los procedimientos UNIFIL para el desminado contemplan que la asistencia de una baja se debe de hacer por un médico antes de 60 minutos.

Como conclusión final y mientras no se reciban las nuevas incorporaciones la introducción de nuevos profesionales en Misiones de Paz con capacitación demostrable, haría que los médicos de la Lista Única - recientemente aprobada- estarían menos sobrecargados en misiones y se podría incluso aumentar el componente etario de despliegue, ya que las solicitudes psicofísicas en zona variarían.

He pretendido, desde mi experiencia de cinco misiones en los últimos cuatro años y medio, dejar abierta una posibilidad de discusión que pueda llevar a paliar la carencia y abandono de médicos desplegables. No obstante, como decía el poeta inglés Alexander Pope (1688-1744): ¿Quién decide cuando los médicos no están de acuerdo?

José Amellugo Catalán Comandante Médico

Comandancia General de Ceuta Clínica Militar de Ceuta 